\title{
ADMINISTRATION DEVELOPMENT OF OMAN ATHLETICS ASSOCIATION
}

\author{
Majid AL-Busafi ${ }^{1}$
}

${ }^{1}$ Physical Education Department, Sultan Qaboos University, Sultanate of Oman

\section{SUMMARY}

The objective of the study understands and highlights the primary administrative issues and barriers occur in the administrative system of Oman Athletics Association. In order to collect the sample, interviews were conducted with the people working in this association. The interviews were conducted with the directors, coaches and employees. The questions asked were related to the problems they faced and what kind of resources is required. The possible solutions according to them were also asked. The participants were divided into three groups, group A consist of employees, group B consist of directors and group $\mathrm{C}$ consist of coaches. The questions were asked according to their field. The results of the study depicted that obstacles faced by the association has the negative impact on the workflow and progress of the organization. There is the need of effective programs in the organization.

Key Words: acreditation, administrative, competencies, complex and structure.

\section{INTRODUCTION}

Administration is an important field in the management of different types of organizations. It is a fundamental department as it facilitates workflow and focuses on achieving goals and objectives of an organization. Any flow in this department may cause failure to the whole system. It is essential to keep continuously developing this department to ensure higher performance levels. However, defects and weaknesses, in real life situations, are expected to occur in any unit of any organization.

The purpose of this study is to identify and understand main administrative issues and obstacles in the administration system of Oman Athletics Association, try to reach possible solutions to overcome these obstacles, and create methods to prevent their recurrence in the future. This ensures the organizations' stability and continues success.

Realizing the obstacles is the first step towards correction. Ignorance and avoidance will not solve the issue. Contrarily, ignorance leads to accumulation of the issues, which most probably will further complicate the problem. When the issue is addressed, it becomes easier and more realistic to search for solu- tions. Sometimes one solution might not be sufficient to solve the problem. That is why a number of possible solutions need to be considered before a final applicable solution is reached. This process is preferably to be done in coordination with a skilled and experienced person in that particular area. That is not the end of the process. A solved issue must be considered as a life lesson. As a result, special techniques must be created in order to ensure that it does not happen again in the future ("Sultan Qaboos", 2007).

The Sultanate of Oman is the second biggest country in the Arab peninsula. Its geographical area is 309.500 square kilometers, and the length of its coastline is approximately $2.092 \mathrm{~km}$. The coastline borders the Indian Ocean and the Arabian Gulf, the Gulf of Oman and the Arabian Sea. The geography of the country provides opportunities for practicing different kinds of sports activities. It has a varied geography and landscape, consisting of sand dunes $(82 \%)$, mountains $(15 \%)$ and plains $(3 \%)$. The weather near the coast is hot and humid in summer, and it is hot and dry in the inland regions, with temperatures reaching an average of $45^{\circ} \mathrm{C}$ in summer. In winter, the weather usually turns to average $25^{\circ} \mathrm{C}$ in most regions ("Oman", 2014). 
The geography of the country has shaped people's activities. The geographical diversity in the Sultanate with its long coasts, valleys, desert and mountains requires different physical attributes and adaptations for each environment. For instance, those who live on the coast understandably focus their activities on the sea and fishing. In addition, those who live in the interior areas, where mountains, desert and valleys dominate, are mainly involved in activities relating to farming and shepherding. Accordingly, populations adapt and achieve the necessary fitness according to each environment (AL-Shamli, 2008). In addition, because of the weather, people in Oman can only start practicing outdoor sport at about the approach of sunset or after that, when the temperature becomes cooler. However, Oman, like other countries in the world, has been affected by technological advances, mechanization and automation, which have radically reduced human physical activity (Ibid). The coastline, which is almost $1.700 \mathrm{~km}$ long, gives opportunities for Omani people to practice beach sports. As a result, it is suggested to give such sports more attention in term of facilities. Hosting the second Asian Beach Games in Muscat ("Muscat", 2014) could be a significant opportunity to build the culture of beach sports among Omani people. It is clearly evident that geographical diversity can affect the lifestyle and economic actions of the inhabitants, and so it is assumed that it may have the same effect on sports activities too (AL-Shamli, 2008).

This increased wealth has led to significant changes since the 1980s for sport in Oman, predominantly for men. The government of Oman has built and developed sports facilities and established organizations for some major Olympic sport. It has fostered interest in sport among regulations to improve conditions for youth, stimulating youth involvement in national, regional and international competitions (AL-Zedjali, 2005). However, it is worth noting that these facilities are only available in some major cities in Oman such as Muscat (the capital) and Salalah city (in the south).

Most of the national organizations for major Olympic sports were established between 1973 and 1988. The national Omani Olympic Committee [OOC] was created in 1982 and joined the International Olympic Committee [IOC] in the same year. Oman first participated in the Olympic Games in 1984 (Ahmed, 1996; AL-Tauqi”, 1998; Ministry of Sports Affairs, 2010).

The last transfer of the sports sector was by Royal Decree 120 in 2004, which created the Ministry of Sports Affairs (Ministry of Legal Affairs, 2010; Ministry of Sports Affairs, 2010). It was set up to work with other relevant bodies; in helping, the Sultanate's youth develop their sporting talents and potential.

All sports federations are voluntary organizations. While many of these federations have a professional salaried staff to manage affairs on a day-to-day basis. Some of the major sports (such as football) have many administrators, those who decide policy are unpaid volunteers elected by members. The methods of election are based on a democratic constitution, which may only be changed by the members of the sport itself (Beashel and Taylor, 1996; Ministry of Sports Affairs, 2010).

The vision and mission of OAA is to achieve sports excellence and honorable representation of the Sultanate of the sports in regional and international events, and to popularize athletics.

Oman Athletics Association [OAA], established in 1982, member of the IAAF since 1982, member of GCC Athletics Organizing Committee since 1986 and member of the Asian Athletics Association [AAA] and the Arab Athletics Association since 1987. In 2010, Oman Athletics the youth, provided trainers and coaches from the external market. They have proposed laws and training center gained the IAAF accreditation as an IAAF ATC Accredited Training Center, which allowed the opportunity for a plenty of international athletes to have their training camps in Muscat.

The General Assembly consists of all affiliated clubs. It meets at least once a year to review activities and events at congress to elect the OAA board of directors once every four years. The current board was elected on November 11, 2012. It consists of nine board members, including Chairman, Sheikh Saif Bin Hilal Al Hosni and General Secretary, Mr. Said Bin Saif Al Qasmi.

OAA plays a significant role in the development of athletic sports in the Sultanate of Oman by preparing qualified coaches and referees and selecting athletes according to a set criterion. It also supervises different local competitions in cooperation with official and civil society institutions. It takes it to its mission to support athletes on the technical, medical and social aspects in order to achieve sports excellence. Further, it works to qualify national technological and managerial cadres to align with international systems and standards. It also works to develop the events and activities of the sport of athletics in Oman.

Since established, OAA has participated in various GCC, Arab, Asian and international competitions. It has participated, as of today, in seven Olympic Games, starting in the 23rd Olympic Games in Los Angeles 
1984, and continued to the 30th Olympic Games in London 2012.

On the other hand, there are numerous Omani youth who work in military sectors who are willing to engage in the game, the prevalent age group in the Sultanate is the youth, increased government funding, in addition to willingness of the privet sector to support and market athletics in Oman. All these factors are promising for a brighter future for the athletics sport in Oman.

Finance: OAA receives its budget (O.R. 600.000 per annum) from Ministry of Sports. It is distributed to cover salaries and wages (O.R. 191.700), variable / administrative (O.R. 40.300) and activity expenses (O.R. 368.000). In addition to that, it has a one-year contract with Muscat Pharmacy, where the latter

\section{TABLE 1}

Human Resources.

\begin{tabular}{llc}
\hline \multicolumn{1}{c}{ Occupations } & Numbers \\
\hline 1. & Board members & 9 \\
\hline 2. & Staff & 8 \\
\hline 3. & Local coaches & 7 \\
\hline 4. & International coaches & 5 \\
\hline 5. & Physiotherapist & 2 \\
\hline 6. & Registered referees & 140 \\
\hline 7. & Active referees & 60 \\
\hline
\end{tabular}

provides minerals and vitamins to the national team worth (O.R. 10.000).

The Table 1 depicts the current HR structure. Work values and principles of Oman Athletics Association consist of the following:

- Transition from management to strategic planning

- Respond to demands of beneficiaries and contributors

- Team work

- Transparency and responsibility

- Diversification in evaluation management

- Respect and protection of human rights

- Maintain Islamic identity

Activities: Every year, OAA organizes / takes place in a number of activates. Local competitions; where clubs compete against each other within their region and only those who are qualified can compete to win OAA cup. Cross-country, school competitions, kid's athletics, road races, social and specialized competitions for women are the primary activities organized by OAA as part of its role and responsibility to activate the sport in the Sultanate. In addition to local activities, OAA takes part in several competitions abroad; GCC, Arab, West Asian, Asian and World Championship.

Table 2 displays the partnership of OAA with other organizations. OAA strategic plan focuses on a number of areas as follows, noting that in this research my focus is on administrative/ managerial area:

- Sport management and supervision.

- Elite sport; supporting athletes, development of training facilities and training camps.

- Events and activities.

TABLE 2

Partnership with Other Organizations.

\begin{tabular}{lrl}
\hline \multicolumn{1}{c}{ Organizations } & \multicolumn{1}{c}{ Organizations } \\
\hline 1. Ministry of Sports & 8. Ministry of Municipality \\
\hline 2. Oman Olympic Committee & 9. Civil Society institutions \\
\hline 3. Sports club & 10. GCC Athletic Association \\
\hline 4. Military sectors & 11. Arab Athletic Association \\
\hline 5. Educational Sectors & 12. Asian Athletic Association \\
\hline 6. Private Sectors & 13. IAAF \\
\hline 7. Media & & \\
\hline
\end{tabular}


TABLE 3

Sport Management and Supervision.

Goals Evaluation Criteria

Distribution of administrative task, job descrip- • Integration of administrative structure.

tions and defining staff duties and responsibi- - Existence of job classification and evaluation melities. thod.

- Increase of e-mail communication between board

Application of e-management principles members.

- Development of website and provide some administrative services (registration forms, reports etc).

- Cooperation in terms of timing local events and

Increase cooperation, communication and trust avoid duplication. with local partners.

- Simplification of administrative procedures to execute events.

Increase abilities to self-financing and create investment and marketing committee.

- Increase of marketing opportunities (facilities, athletes, services and events).

- Seasonal marketing contracts.

Develop the culture of teamwork in event management.

- Activation of sub-committees and attraction of professional personals.

- Establishing work teams for executive projects.

- Modification of rewards and allowances system for

Modify some of the existing internal regulations. administrative and technical staff.

- Development of athletics; developing technical and administrative staff, athletics for all, kid's athletics, athletics for women and awareness.

Table 3 presents the goals of OAA and its evaluation criteria.

\section{METHODS}

The field study of this research involved interviews across the Association, through which realities, problems, needs, possible solutions and ideas were discussed with those currently working in the athletics field in Oman. Interviews were conducted with (7) persons of OAA Employees, (7) Directors and (10) Coaches from Oman Athletics Association. The interviews were conducted during May 2013 in Muscat.

The aim of this study is to identify and understand main administrative issues and obstacles in Oman Athletics Association, and to reach for possible solutions to overcome the obstacles, as well as to eliminate possible future occurrence of these obstacles. The questions asked of the participants varied between issues concerning planning, organizing, coordinating, and leadership.

The questionnaires mainly contained three types of questions, for three different groups in the Association. The first group consisted of the employees of the Association (those with permanent contracts).
The second group included directors while the third group consisted of coaches.

Participants in Group A (Employees) were given a number of questions to measure their satisfaction, understanding of their role, having a clear understanding of the Association objectives and level of coordination in the system of the Association. They were asked to rate these aspects in terms of good, acceptable or poor.

Group B (Directors) were given a number of general administrative obstacles and were asked to give their opinion whether those obstacles do exist, somewhat or do not exist.

In Group B (Coaches), considered as beneficiaries, were requested to rate the services provided by coaches and their athletes, whether they were good, acceptable or poor.

\section{RESULTS}

Results of the field study will be discussed in detail concerning the administrative obstacles facing OAA, obstacles that have negative influences on the progress of the workflow and may disturb competencies and effectiveness in the administration system.

The results show that most of the respondents (employees, management and coaches) agreed that administration issues and obstacles do exist in the administrative system of the Association. 


\section{Group A}

Most employees of Oman Athletics Association agreed that the procedures to carry out works in the Association are easy. Contrarily they think that the availability of an atmosphere that encourages creativity and innovation is poor. The majority of the employees believe that these aspects are acceptable; participation of staff in decision-making, existence of a clear hierarchal system, cooperation and friendly relations between employees. In regards to the availability of information and easy access to them should be given whenever needed, suitability of financial resources in order to improve workflow and all of them agreed that financial rewards in comparison to work responsibilities are acceptable.

Table 4 shows the outcome of the questionnaires with the staff of OAA.

The majority of the employees find it difficult to perform their jobs due to:

- Job role and responsibilities are not clear.

- The way work is distributed.

The employees believe that the following are urgent issues that need to be solved in the Association:

- Slow in workflow due to delays in decisionmaking

- Distribution of work
- Cooperation at work

\section{Group B}

The majority of OAA directors agreed that these obstacles do exist in the Association. Improvisation in conducting work, weakness in evaluation process, weakness in planning, confused hierarchal system and lack of coordination between employees and supervisors are major issues. Most respondents implied that these obstacles somewhat existed in the Association; unclear objectives, weakness in human resources, lack of horizontal and vertical coordination, workflow is slow and procedures are complicated. The lack of innovation and creativity, lack of unity in the way works are conducted, coordination is not sufficient to prevent inconsistency and redundancy, and administrative procedures are bureaucratic.

A good number of respondents believe that centralization of authority and autocratic procedures do not exist in the Association.

Table 5 shows detailed findings resulted from interviews with directors at OAA.

\section{Group C}

As it is shown in the table below, most coaches agreed that speed of work performance, speed of

TABLE 4

The questionnaires with the staff of $O A A$.

\begin{tabular}{|c|c|c|c|}
\hline \multirow{2}{*}{ Question Addressed } & \multicolumn{3}{|c|}{ Ratings (No. out of 7) } \\
\hline & Good & Aceptable & Poor \\
\hline 1. Participation of staff decision & 1 & 4 & 2 \\
\hline 2. Clear hierarchal system & 0 & 4 & 3 \\
\hline 3. Division of work & 2 & 2 & 3 \\
\hline $\begin{array}{l}\text { 4. How serious and honest is the relationship of the } \\
\text { employees and the management }\end{array}$ & 2 & 3 & 2 \\
\hline $\begin{array}{l}\text { Cooperation and friendly relation of the employees } \\
\text { with each other }\end{array}$ & 3 & 4 & 0 \\
\hline $\begin{array}{l}\text { 6. Cooperation and friendly relation of the employees } \\
\text { with each other }\end{array}$ & 3 & 2 & 2 \\
\hline 7. Clarity of role and responsibilities of employees & 2 & 2 & 3 \\
\hline 8. Easy procedures to conduct work & 5 & 2 & 0 \\
\hline 9. Availability of information and easy access when in need & 0 & 4 & 3 \\
\hline $\begin{array}{l}\text { 10. Availability of an atmosphere that encourages creativity } \\
\text { and innovation }\end{array}$ & 0 & 3 & 4 \\
\hline $\begin{array}{l}\text { Availability of suitable work requirements to improve } \\
\text { work conditions }\end{array}$ & 2 & 5 & 0 \\
\hline 12. Suitability of financial resources in order to improve workflow & 0 & 6 & 1 \\
\hline $\begin{array}{l}\text { Financial reward is appropriate in relation to your } \\
\text { work responsibility and hours of work. }\end{array}$ & 0 & 7 & 0 \\
\hline
\end{tabular}


fulfilling needs of coaches, flexibility in responding to needs, ability to accomplish work, suitability of services provided and the ability to provide services in a sufficient way are acceptable, however can be improved in the future. Six out of ten coaches think that OAA is poor in taking care of beneficiaries, delegation and transparency with coaches. Five coaches believe that speed of decision making by the management of $\mathrm{OAA}$ is poor, equally five coaches believe the same aspect is acceptable.

Table 6 shows results found in interviews with OAA coaches:

\section{RESULTS}

General findings confirmed that there are obstacles in the administration system of the Association. The existence of obstacles is normal in any organization. However, solutions and ways to overcome these obstacles are necessary in order for the organization to continue providing its services efficiently.
The results of the study show that one major issue behind the occurrence of those obstacles in the Association is lack of planning. Planning is an essential element in the management of organizations. Planning focuses attention on objectives and results, and so it gives necessary direction to the future activities. It reduces mistakes and unnecessary pressures and ensures greater productivity. Good planning provides guidance to decision-making. Lack of planning is one of the reasons behind issues like lack of communication, lack of coordination. Planning facilitates communication and coordination between different departments in an organization. Lack of planning leads, as well, to delays in decision-making at the Association.

The suggested IAAF coach education model is split into five levels of accreditation, framing progressive responsibilities, competencies and capabilities from foundation to level five. The 5-level structure addresses the weakness of the old 3-level structures that are criticized for minimizing the opportunities for providing qualified coaches at different levels of

TABLE 5

Results from interviews with directors at $\mathrm{O} A A$.

\begin{tabular}{|c|c|c|c|}
\hline \multirow[b]{2}{*}{ Question Addressed } & \multicolumn{3}{|c|}{ Ratings (No. out of 7) } \\
\hline & Exist & $\begin{array}{c}\text { Somew- } \\
\text { hat }\end{array}$ & $\begin{array}{c}\text { Do not } \\
\text { exist }\end{array}$ \\
\hline 1. Objectives are not clear & 3 & 4 & 0 \\
\hline 2. Lack of criteria to determine priorities & 3 & 2 & 2 \\
\hline 3. Improvisation in work conduct & 4 & 1 & 2 \\
\hline 4. Weakness in human resources & 1 & 5 & 1 \\
\hline 5. Lack of horizontal and vertical coordination & 2 & 4 & 1 \\
\hline 6. Weakness in monitoring and evaluation process & 6 & 0 & 1 \\
\hline 7. Weakness in planning & 5 & 2 & 0 \\
\hline 8. Lack of qualifications for those in the position of planning & 3 & 3 & 1 \\
\hline 9. Centralization of authority & 2 & 1 & 4 \\
\hline 10. Slow workflow and complicated procedures & 3 & 4 & 0 \\
\hline 11. Lack of creativity and innovation & 3 & 4 & 0 \\
\hline 12. Autocratic procedures & 1 & 2 & 4 \\
\hline 13. Responsibility is not distribute among the leaders & 1 & 3 & 3 \\
\hline 14. There is no unity in the way work is conducted & 2 & 5 & 0 \\
\hline 15. Hierarchy system is not clear & 5 & 1 & 1 \\
\hline 16. Job description is not clear & 2 & 3 & 2 \\
\hline 17. Shortage in human and material resources & 3 & 3 & 1 \\
\hline 18. Lack of coordination between employees and supervisor & 4 & 2 & 1 \\
\hline $\begin{array}{l}\text { Coordination does not prevent inconsistencies } \\
\text { and redundancies }\end{array}$ & 1 & 5 & 1 \\
\hline 20. Administrative procedures and bureaucratic & 3 & 4 & 0 \\
\hline
\end{tabular}


TABLE 6

Interviews with $O A A$ coaches.

\begin{tabular}{llrc}
\hline \multirow{2}{*}{ Question Addressed } & \multicolumn{2}{c}{ Ratings (No. out of 7) } \\
\cline { 2 - 4 } & Good & Aceptable & Poor \\
\hline 1. Speed of work performance & 1 & 6 & 3 \\
\hline 2. Speed of fulfilling needs & 1 & 6 & 3 \\
\hline 3. Flexibility in responding to needs and development & 2 & 8 & 0 \\
\hline 4. Ability to accomplish the world & 2 & 7 & 1 \\
\hline 5. Suitability of services provided to beneficiaries needs & 1 & 7 & 2 \\
\hline 6. Provide services in sufficient way & 1 & 6 & 3 \\
\hline 7. Taking care of beneficiaries & 1 & 3 & 6 \\
\hline 8. Transparency & 2 & 2 & 6 \\
\hline 9. Speed of decision making & 0 & 5 & 5 \\
\hline 10. Delegation & 1 & 2 & 7 \\
\hline
\end{tabular}

sports program. The matrix is completed with four 'sites' at which coaches could be involved in participation, performance or competitive sport: local, regional, national or international. One of the great advantages of this new structure is that, in addition to provision for elite coach development for international competition, it provides the opportunity for coaches to qualify at level five. It will remain working at grass roots level whilst gaining higher-level qualifications, allowing them to use their increasingly complex skills and knowledge at a local level. The matrix structure addresses criticisms of the pyramid style models that are viewed as elitist and lacking in vision regarding the need for sophisticated skill sets to work in community/participation sites. This structure is one of the most valuable outcomes of the current study and addresses the first principle, to commit to the provision of high quality active, trained and accredited coaches to ensure that participants, performers, and competitors involved in sport have access to the best coaching at each stage of their development.

\section{DISCUSSION}

General findings confirmed that there are obstacles in the administration system of the Association. The existence of obstacles is normal in any organization. However, solutions and ways to overcome these obstacles are necessary in order for the organization to continue providing its services efficiently.

The results of the study show that one major issue behind the occurrence of those obstacles in the Association is lack of planning. Planning is an essential element in the management of organizations. Planning focuses attention on objectives and results, and so it gives necessary direction to the future activities. It reduces mistakes and unnecessary pressures and ensures greater productivity. Good planning provides guidance to decision-making. Lack of planning is one of the reasons behind issues like lack of communication, lack of coordination. Planning facilitates communication and coordination between different departments in an organization. Lack of planning leads, as well, to delays in decision-making at the Association.

The suggested IAAF coach education model is split into five levels of accreditation, framing progressive responsibilities, competencies and capabilities from foundation to level five. The 5-level structure addresses the weakness of the old 3-level structures that are criticized for minimizing the opportunities for providing qualified coaches at different levels of sports program. The matrix is completed with four 'sites' at which coaches could be involved in participation, performance or competitive sport: local, regional, national or international. One of the great advantages of this new structure is that, in addition to provision for elite coach development for international competition, it provides the opportunity for coaches to qualify at level five. It will remain working at grass roots level whilst gaining higher-level qualifications, allowing them to use their increasingly complex skills and knowledge at a local level. The matrix structure addresses criticisms of the pyramid style models that are viewed as elitist and lacking in vision regarding the need for sophisticated skill sets to work in community/participation sites. This structure is one of the most valuable outcomes of the current study and addresses the first principle, to commit to the provision of high quality active, trained and accredited coaches to ensure that participants, performers, and competitors involved in sport have 
access to the best coaching at each stage of their development.

\section{CONCLUSON}

As the aim of this study was to identify the obstacles that affect the workflow at Oman Athletics Association, explore ways to overcome the obstacles and find techniques to avoid recurrence in the future. Following are some recommendations for a successful administration system. The recommendations are divided into two parts; general recommendations and specialized recommendations in the area of human development.

Currently, sport and all its activities in Oman are under the supervision of the Ministry of Sport Affairs, to which the sports federations report. From an organizational, administrational and functional point of view, these sports federations control and supervise all sports clubs in Oman with financial support from the Ministry of Sports Affairs. The sports federations are the supreme bodies that govern sports clubs, and their main task is to develop and promote the sport they represent.

\section{General Recommenadaton}

Vision, mission and objectives of the Association must be clear to all the stakeholders, especially employees, to enable their efforts to achieve the objectives through the process of management. Regular meetings between management and the employees, management and the coaches are necessary. In these meetings, needs, plans, progress reports and achievements should be discussed. This will facilitate communication and leads to mutual understanding between different parties/departments in the Association.

Simplify procedures and avoid bureaucracy as much as possible. The process of decision-making needs to be improved and it should be more flexible to enable quick response to the needs of coaches and athletes. Activating electronic communication between board members, staff and member of the committees is highly important to make decisions faster, since board members and most members of different committees are volunteers who are committed to full time jobs.

Delegation of authority is a very important tool to make workflow easier and faster.

Work division among employees must be on an equal and fair basis. There should be transparency in the relations between the management and employees, the management and coaches as well as the employees and coaches. This can increase trust between the different parties. Promote teamwork, by creating an environment where everybody works collaboratively and in coordination to achieve the objectives through the process of management. Unity of command, as discussed earlier, in accordance with Fayol's theory of management principles, each individual must have only one direct supervisor or manager, from whom directions are taken. Use of expertise houses in the field of administration, and establishing exchange programs with local and regional sports associations.

\section{Future Research}

With the aim of this study to explore administrative issues, other topics come up to be studied in the future. It is important to study performance development plan. Any type of organization, especially sports organizations, need a risk management plan. In the future researches, developing a human resources strategy and action plan will be beneficial.

\section{REFERENCES}

Ahmed, B. (1996). Oman sport and Olympiad. Muscat, Alwatan: Omani Olympic Committee.

AL-Shamli, A. (2008). The effectiveness of after-school physical activities on the physiological fitness components of 10th grade male students in Al-Dhabirah Region, Sultanate of Oman.Unpublushed doctoral thesis, University of Malaya.

AL-Tauqi, M. (1998). Organizational effectiveness: Oman Football Association. Ottawa, Canada: University of Ottawa.

AL-Zedjali, Y. (2005). Omani sport. From the beginning to universal. Muscat, Oman: Ministry of Sport Affairs.

Beashel, P., \& Taylor, J. (1996). Advanced studies in physical education and sport. London, Unted Kngdom: Nelson.

Ministry of Legal Affairs. (2010). The Royal Decree No. 112/2004: Establishing the Ministry of Sports Affairs. Muscat, Oman: Ministry of Legal Affairs.

Ministry of Sports Affairs (2010). Omani sports bistory. Muscat. Oman: Ministry of Sport Affairs.

Muscat. (2014). The second Asian Beach Games. Retrieved from http://www.muscat2010.org . om/ar/Pages/ default.aspx.

OMAN. (2014). Muscat: Ministry of Information, Oman establishment for Press, Publication \& Advertising. 
Sultan Qaboos University. (2007). Self Study Report. College of Education Physical Education Department.
Retreived from http://www.squ.edu.om/ portals/43/selfstudyphysical.pdf

Received: February 11, 2015

Revision received: May 29, 2015

Accepted: May 29, 2015

Correspondence to: Majid AL-Busafi

Physical Education Department,

Sultan Qaboos University

Muscat, Oman-32AL-Khod-123

Phone: 0096899444661

E-mail: majed_busafi@yahoo.com 